\title{
Environmental and Safety Accidents Related to Blasting Operation
}

\author{
${ }^{1}$ Lazar Kricak, ${ }^{2}$ Vladislav Kecojevic, \\ ${ }^{1}$ Milanka Negovanovic, ${ }^{1}$ Ivan Jankovic and ${ }^{1}$ Dario Zekovic \\ ${ }^{1}$ Department of Mining Engineering, Faculty of Mining and Geology, \\ University of Belgrade, 11000 Belgrade, Serbia \\ ${ }^{2}$ Department of Mining Engineering, \\ College of Engineering and Mineral Resources, \\ West Virginia University, Morgantown, WV 26506, USA
}

Received 2012-02-03; Revised 2012-05-12; Accepted 2012-06-18

\begin{abstract}
The blasting process remains a potential source of numerous environmental and safety accidents. The majority of these accidents were contributed to the flyrock and lack of blast area security. A field-scale investigation related to flyrock accident was conducted in an andesite quarry where rocks up to $50 \mathrm{~cm}$ in diameter were propelled almost $300 \mathrm{~m}$ from the center of blasting field causing extensive damages to the surrounding objects. The study revealed that accident occurred due to the existence of andesite alteration in one section of the blast field. The existence of this alteration caused a sliding of rock masses along the subsistent joint planes and thereby reduced burden for the second row of blastholes. Alterations involved small area of andesite masses that were not detected by previous geological exploration or visually observed prior to initiation of blastholes. The result of this filed investigation should have a positive impact on hazard awareness, prevention and safe blasting practices in mining and construction industries.
\end{abstract}

Keywords: Blasting, quarry andesite rocks, flyrock, area security, environmental and safety accidents

\section{INTRODUCTION}

The main purpose of blasting operations in mining and civil engineering projects is the rock fragmentation. This process provides appropriate material granulation that will be suitable for excavation and transportation.

The blasting process, however, remains a potential source of numerous environmental and safety accidents. Even though the mining industry has improved its environmental and safety record, there are still reports indicating blasting-related accidents involving both people and various objects. For instance, the Mine Safety and Health Administration (MSHA, 2006) reports a total of 168 blasting related injuries in the United States from 1994 through 2005. A total of 107 injuries occurred in surface coal, metal and non-metal mining, while 61 injuries were reported for underground mining. Analysis conducted by Verakis and Lobb (2007) shows that in surface mining 39 accidents were directly attributed to lack of blast area security, 32 to flyrock, 15 to premature blast, nine to misfires, one to disposing and seven to miscellaneous blasting-related accidents. It can be noted that almost $70 \%$ of all injuries is directly contributing to the flyrock and lack of blast area security. Study conducted by $\mathrm{Lu}$ et al. (2000) indicates that almost $27 \%$ of demolition accidents in China were contributed to flyrock, while Adhikari (1999) reports that $20 \%$ of accidents that were related to flyrock occurred in mines in India.

Blast area is the area in which shock wave, flying material, or gases from an explosion may cause injury to humans and damage to various objects. The flyrock is defined as the rock propelled beyond the blast area by the force of an explosion (IME, 2007). When these rock fragments are thrown beyond the allowable limits they result in human injuries, fatalities and structure damages. These rocks can travel distances of more than $600 \mathrm{~m}$ at speeds of almost $650 \mathrm{~km} \mathrm{~h}^{-1}$ (Verakis and Lobb 2007). 
Several studies including Bajpayee et al. (2000; 2004), Fletcher and D'Andrea (1986), Kecojevic and Radomsky (2005), Moore and Richards (2005), Rehak et al. (2001), Shea and Clark (1988), Siskind and Kopp (1995) and Verakis and Lobb (2007) revealed that flyrock is caused by one or more of the following factors: (i) discontinuity in the geology and rock structure, (ii) improper blasthole layout and loading, (iii) insufficient burden, (iv) very high explosive concentration, (v) inadequate stemming and (vi) inadequate delay time.

The rock structure and rock properties may vary considerably from a location to location even within the same blast area. Discontinuity in the geology and rock structure causes a mismatch between the explosive energy and the resistance of the rock. Existence of fissures, joints and weaknesses are likely to assist in the creation of flyrock.

Insufficient burden is one of the primary causes of flyrock. Too short a distance to the bench slope wastes energy, while too great a burden distance causes improper fracturing of the rock, creating oversize boulders. Due to irregularity of bench slopes, energy generated during blasting poses the hazard at the weakest point of the bench. Furthermore, any deviation during the drilling process can increase or reduce the burden. In small mining and civil engineering operations, the lack of the knowledge and accurate technology to identify and recognize the specific anomaly or weakness in the rock structure that leads to the subsequent flyrock problem.

Blasthole overloading is one of the frequent causes of flyrock occurrence. Such overloading generates excessive release of energy. It appears due to the loss of powder in voids, caverns and cavities. Stemming material provides confinement and prevents the escape of high-pressure gases from the blastholes. If the stemming length to hole diameter ratio is too small or collar rock is weak, flyrock can be projected in any direction from the crater of the blasthole.

\section{MATERIALS AND METHODS}

A recent environmental and safety accident occurred at an andesite quarry. Rocks up to $0.5 \mathrm{~m}$ in diameter were propelled almost $300 \mathrm{~m}$ from the center of blasting causing extensive damages to the surrounding objects. Figure 1 shows the position of the objects that were damaged during the blasting process, while Fig. 2 shows both external and internal damages of one of the objects strucked by the flyrock. Various sizes of the rocks found at the damaged objects are given in Fig. 3.

The field-scale investigation on this flyrock accident was conducted. Appropriate measures, education and training procedures that will need to be taken to avoid similar accidents in the future are also discussed.

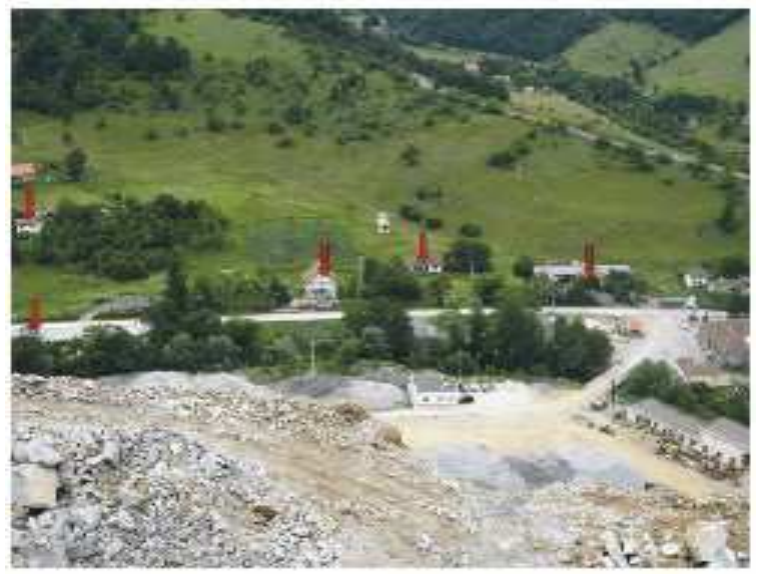

Fig. 1. Position of the objects damaged by the flyrocks
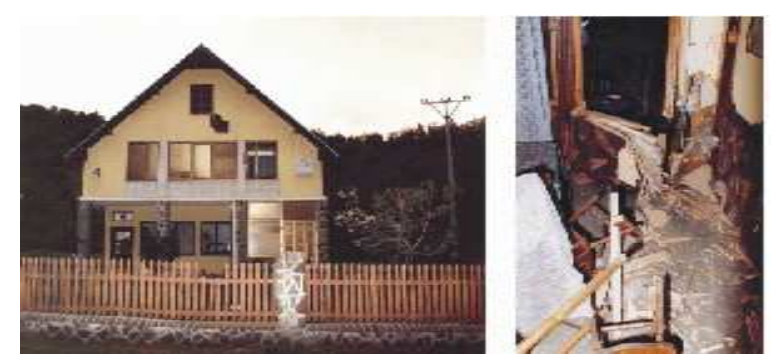

Fig. 2. External and internal view of the objects damaged by the flyrocks

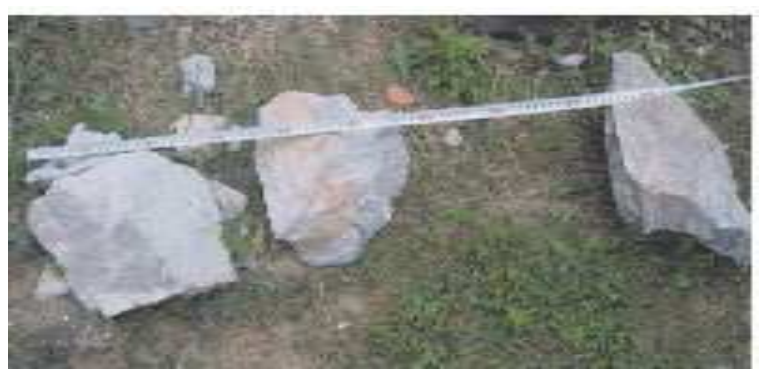

Fig. 3. Flyrocks found at the damaged objects

\section{RESULTS}

Field-scale investigation has revealed that blasting operation at the quarry was performed at three benches with a total of five (I-V) blasting sections.

Table 1 shows number of blastholes, length, stemming, explosive charge and explosive type for each of the blasting sections. A total of $4467 \mathrm{~kg}$ of explosives was used, i.e., $542 \mathrm{~kg}$ of Emulgit $82 \mathrm{GP}$ and $3925 \mathrm{~kg}$ of Emulgit Emex AN. 
Table 1. Blasting parameters for all sections

\begin{tabular}{lllll}
\hline Section & Number of blastholes & Length of hole $(\mathrm{m})$ & Stemming $(\mathrm{m})$ & Explosive charge $(\mathrm{kg} / \mathrm{hole})$ and explosive type \\
\hline I & 7 & 3.0 & 2.6 & 2 (Emulgit 82 GP) \\
II & 66 & 15.5 & 2.8 & 6 (Emulgit 82 GP) \\
& & & & $55-57.5$ (Emulgit Emex AN) \\
III & 8 & 3.0 & 2.6 & 2 (Emulgit 82 GP) \\
IV & 5 & 4.0 & 2.8 & 2 (Emulgit 82 GP) and 2 (Emulgit Emex AN) \\
& 5 & 4.5 & 2.8 & 2 (Emulgit 82 GP) and 5 (Emulgit Emex AN) \\
& 5 & 5.0 & 2.8 & 2 (Emulgit 82 GP) and 7.5 (Emulgit Emex AN) \\
& 5 & 5.5 & 2.8 & 2 (Emulgit 82 GP) and 10 (Emulgit Emex AN) \\
V & 5 & 6.0 & 2.8 & $2-4$ (Emulgit 82 GP) and 10-12.5 (Emulgit Emex AN) \\
& 4 & 4.5 & 2.8 & 4 (Emulgit 82 GP) and 2.5 (Emulgit Emex AN) \\
& 4 & 4.5 & 2.8 & 4 (Emulgit 82 GP) and 5 (Emulgit Emex AN) \\
& 4 & 5.5 & 2.8 & 4 (Emulgit 82 GP) and 7.5 (Emulgit Emex AN) \\
& 3 & 6.0 & 2.8 & 4 (Emulgit 82 GP) and 10 (Emulgit Emex AN) \\
\hline
\end{tabular}

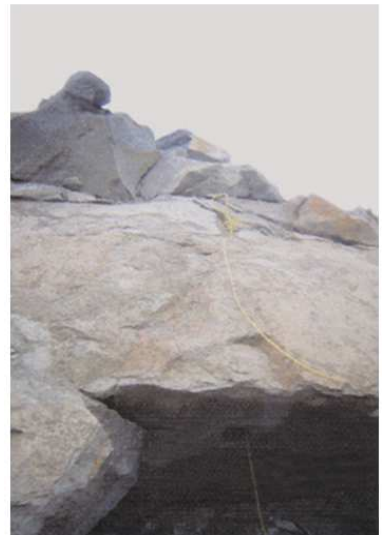

Fig. 4. Overhangs with two explosive cartridges in the stemming zone of the blastholes at the end of blasting section II

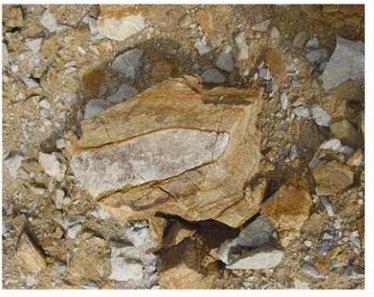

(a)

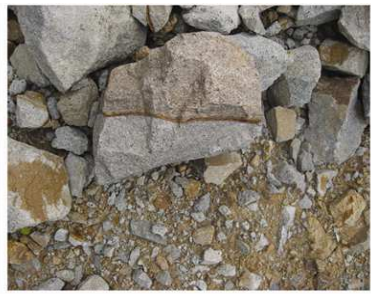

(b)
Fig. 5. Fresh andesite within alteration zone (a) and partial alteration of andesite (b)

The parameters of the largest section-blasting section II were: bench height $13.6 \mathrm{~m}$, blasthole length $15.5 \mathrm{~m}$, subdrilling $1 \mathrm{~m}$, burden $2.8 \mathrm{~m}$, spacing between blastholes in a same row $3 \mathrm{~m}$, spacing between rows $2.8 \mathrm{~m}$, blasthole diameter $89 \mathrm{~mm}$ and angle of blastholes $70^{\circ}$.
Fig. 6. The relic of fresh andesite in altered andesite mass at the bench slope

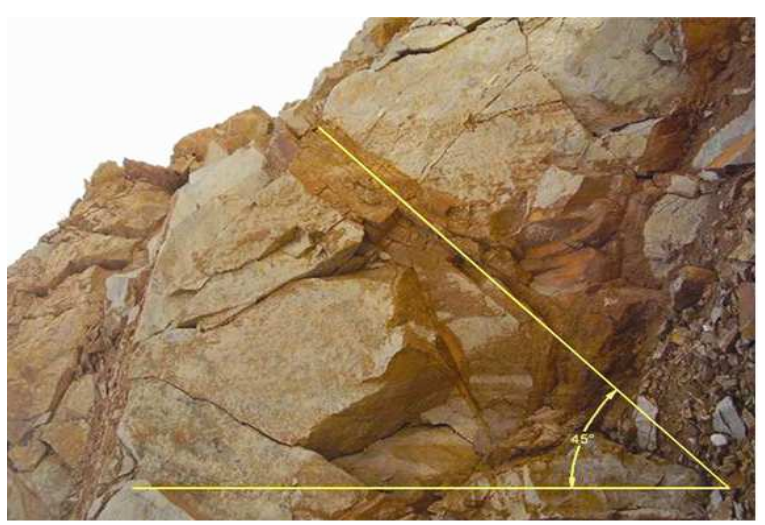

Fig. 7. Unaltered andesite within alteration zone

Blasting was performed in andesite rocks. The uniaxial compressive strength of andesite in dry condition varies from 106-232 MPa. Extremely low values of compressive strength are related to altered andesite. 
The mean uniaxial compressive strength of andesite in dry condition is 177 and $165 \mathrm{MPa}$ in wet condition. The density of andesite is in a range from $2.52-2.65 \mathrm{~g} \mathrm{~cm}^{-3}$. The high density values are related to unaltered andesite. The initiation is started from blasting section I on the lowest bench, followed by sections II, III, IV and V, respectively.

\section{DISCUSSION}

The field investigation after the accident revealed the existence of the overhangs with two explosive cartridges in the stemming zone at the end of blasting section II (Fig. 4). At the muckpile of blasted rocks at section II, a significant number of fragments with a high degree of andesite alteration were found (Fig. 5). On the bench slope of the same blasting section, the relic of fresh andesite in altered andesite mass was observed (Fig. 6). Figure 7 shows unaltered andesite within alteration zone where the angle between horizontal line and the fracture filled by altered material is $45^{\circ}$.

Based on the previous field observation, the model of blasting section II was created (Fig. 8. and 9). Analyzing the model and the maximum flyrock throw distance, it was concluded that the major contributing factor to the accident was the existence of andesite alteration in blasting section II. The existence of this alteration caused a sliding of rock masses along the subsistent joint planes and thereby reduced burden for the second row of blastholes. Since the blastholes were loaded with the amount of explosives for designed value of burden, an excessive release of explosives' energy during blasting process resulted in flyrock from the bench slope. Aditionally, unloaded muckpile from previous blasting operation increased the resistance on the bottom of the blastholes and thereby forced high-pressure gases to extend upwards. Contributing factor to flyrock occurrence was also the congruence of the joint angle at the contact between unaltered and altered andesite and drilling angle, which enabled easier sliding of part of the rock masses by the existing fracture planes. One of the factors that influenced the increase of throw distance was the angle of 45 degrees between the horizontal line and the fracture filled with altered material. It is well-known from the trajectory analysis that the throw will reach the maximum value when the launch angle is $45^{\circ}$.

The accident investigation should result in the identification of the cause followed by the appropriate response or correction in procedure.

It is very important that the surface rock is inspected for faults and planes before hole charging. Previous excavations can give significant information about the rock structure. Base information (e.g., consolidation, voids) regarding the rock structure and properties of the material to be blasted can be routinely obtained from drill hole logs and must be considered prior to hole loading. Best-in-class safety performance can be achieved when regular geologic hazard or exception mapping occurs by trained foremen and/or mine geologists. Incorporating geologic variability can be routine by including exception mapping into the periodic stripping plan. Most mining operations plan sequencing and stripping on a weekly to a monthly basis.

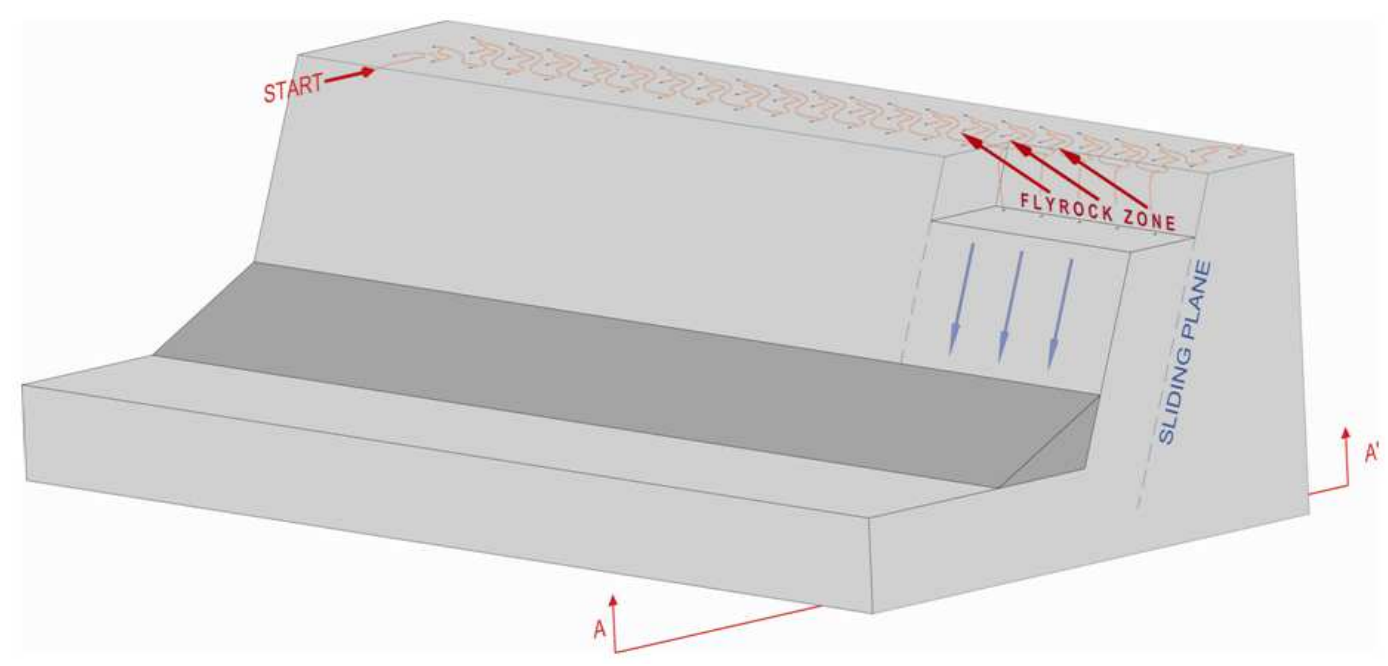

Fig. 8. Model of blasting section II 


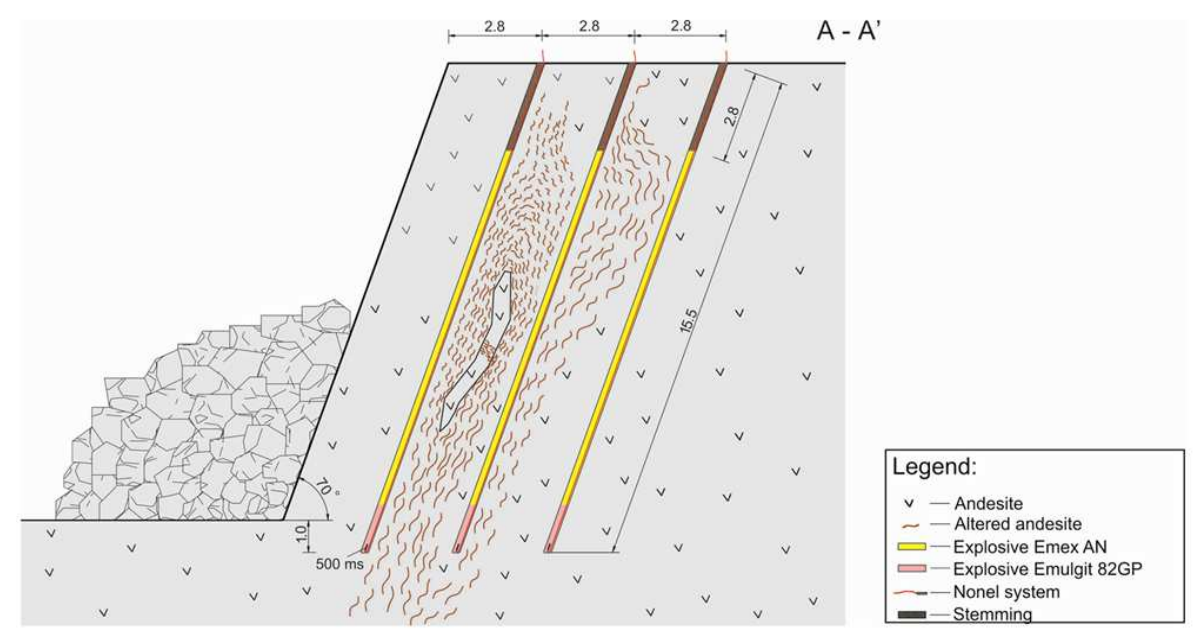

Fig. 9. A cross sectional view of blasting section II with the position of unaltered and altered andesite masses

Gathering records during the drilling process and of crucial importance. A Global Positioning System (GPS) installed on the drill system can provide the precise locations of boreholes drilled. Each borehole can be surveyed to provide an as-built record of the drilling accuracy accomplished at each location. The operator also can provide the on-the-spot assessment of situations that result in drill downtime, or unusual performance of the system at the given location. In such an arrangement, the machine location, changes in geology, unusual rock strata features and machine defects could all be documented at the same setting.

The Aquila Mining Systems (AMS) have developed a production monitoring system, a material recognition system and a guidance system for vertical and inclined drilling. The production monitoring system provides the operator with immediate information on drilling productivity and performance, while the material recognition system is equipped with vibration sensors and pattern recognition software to determine the hole geology while drilling. Guidance systems for vertical and inclined drilling enable the operator to position the blast hole with a high accuracy.

In order to prevent hole overloading, it is necessary to load holes as designed using the correct charge weight. Additionally, a blast ratio should be ensured sufficiently high to eliminate the possibility of excessive charging and holes have to be monitored to check the rise of the powder. In the case of reduced burden, more intermediate stemming should be applied. The efficiency of stemming will mostly depend upon its length (Kricak et al., 1996). In general, the stemming length should be not less than 25 times the blast hole diameter (Sheridan, 2002). Konya and Walter (1990) recommend a stemming length of 0.7 times the burden. If there are fractured rocks in the collar zone of the hole, they must be removed before hole initiation in order to prevent cratering. Probability of flyrock occurrence can also be reduced by hole initiation from the bottom rather than from the top.

The issue of blast area security can be successfully addressed by providing appropriate training and education of personnel involved in blasting operations to apply the best safety practices, as well as government regulations. Furthermore, blast area must be inspected to determine distances to nearby structures, roads, public places and due consideration must be taken in determining the degree of protection necessary. It is of primary importance to clear all employees from the blast area, guards should be posted at the entrance to all access roads leading to the blast area and blaster should communicate to the foreman about the impending blast. The blaster must go outside the blast area or stay inside a blasting shelter and after receiving the feedback from the foreman and guards, blast signal needs to be sounded. Furthermore, ample warning shall be given before blasts are fired and all persons shall be cleared and removed from the blast area unless suitable blasting shelters are provided to protect persons endangered by concussion or flyrock from blasting. Effectively training the workforce in hazard recognition and avoidance and the safe use of explosives is an essential activity in reducing accidents. 


\section{CONCLUSION}

The historical trend over the last decade is a general decrease in the number of environmental and safety accidents from the blasting operations. Even though these accidents for all types of mining operations have declined, they continue to occur and cause human injuries and damages to surrounding structures.

Case study discussed in this study revealed that the accident is caused by discontinuity in the geology and rock structure. The existence of andesite alteration in blasting section caused a sliding of rock masses along the subsistent joint planes and thereby reduced the burden of the blastholes.

During the blasting operations in rock masses where discontinuities in the geology and rock structure exist, it is very important to properly adjust blasting pattern, type and amount of explosives to be used, apply adequate stemming material and provide an appropriate stemming length and burden. Detail geological exploration, using the advance systems for monitoring of drilling parameters is of primary interest in order to gather accurate information about the rock properties.

Training and education of personnel involved in blasting operations play a critical role in preventing environmental and safety accidents and should be focused on: codes and standards, workplace responsibility, assessing and developing accident prevention strategies, developing workplace safety procedures, implementing work practices that meet specified legislation and standards, identifying strategies for monitoring and updating safety information and effective safety communications.

\section{REFERENCES}

Adhikari, G.R., 1999. Studies on flyrock at limestone quarries. Rock Mech. Rock Eng., 32: 291-301. PMID: 16948459

Bajpayee, T.S., T.R. Rehak, G.L. Mowrey and D.K. Ingram, 2000. A summary of fatal accidents due to flyrock and lack of blast area security in surface mining, 1989-1999. Proceedings of the 28th Annual Conference on Explosives and Blasting Technique, International Society of Explosives Engineers, Feb. 10-13, NIOSH, Las Vegas, Nevada, pp: 105-188.

Bajpayee, T.S., T.R. Rehak, G.L. Mowrey and D.K. Ingram, 2004. Blasting injuries in surface mining with emphasis on flyrock and blast area security. J. Safety Res., 35: 47-57.
Fletcher, L.R. and D.V. D'Andrea, 1986. Control of flyrock in blasting. Proceedings of the 12th Annual Conference on Explosives and Blasting Technique, International Society of Explosives Engineers, Feb. 10-13, NIOSH, Las Vegas, Nevada, pp: 167-177.

IME, 2007. Glossary of commercial explosives industry terms. 1st Edn., Institute of Makers of Explosives. pp: 51.

Kecojevic, V. and M. Radomsky, 2005. Flyrock phenomena and area security in blasting-related accidents. Safety Sci., 43: 739-750. DOI: 10.1016/j.ssci.2005.07.006

Konya, C.J. and E.J. Walter, 1990. Surface Blast Design. Prentice Hall Inc., NJ, ISBN-10: 0138779945, pp: 303.

Kricak, L., N. Purtic and M. Boskovic, 1996. Influence of blastohole stemming on degree of potential explosive energy use. Proceedings of the 3th International Scientific Conference on Surface Mining, (SM' 96), Belgrade, Serbia: pp: 254-263.

Lu, W., S. Lai and J. Li, 2000. Study on flyrock control in bench blasting. J. Wuhan Univ. Hydr Elec. Eng., 33: 9-12.

Moore, A.J. and A.B. Richards, 2005. Flyrock control and calibration of a predictive model. Kalgoorlie Consolidated Gold Mines.

MSHA, 2006. Accident data abstracts, mine blasting fatal and nonfatal accident reports, 1978-2005. Mine Safety and Health Administration.

Rehak, T.R., T.S. Bajpayee, G.L. Mowrey and D.K. Ingram, 2001. Flyrock issues in blasting. Proceedings of the 27th annual Conference on Explosives and Blasting Technique, (EBT' 01), International Society of Explosives Engineers, Cleveland, OH, pp: 165-175.

Shea, C.W. and D. Clark, 1988. Avoiding tragedy: Lessons to be learned from a flyrock fatality. Coal Age., 103: 51-54.

Sheridan, R.A., 2002. Precautions against Flyrock. Explosives International Bulletin, Explosives Inspectorate, Safety and Health Administration, Queensland Government.

Siskind, D.E. and J.W. Kopp, 1995. Blasting accidents in mines: A 16 year summary. Proceedings of the $21 \mathrm{st}$ Annual Conference on Explosives and Blasting Technique, (EBT' 95), International Society of Explosives Engineers, Cleveland, OH, pp: 224-239.

Verakis, H. and T. Lobb, 2007. Flyrock revisited: An ever-present danger in mine blasting. Proc. Ann. Conf. Exp. Blasting Technique, 1: 87-96. 